\title{
COVID-19 Myocarditis Clinical Presentation, Diagnosis and Management: A Narrative Review
}

\author{
Elie Al Zaghrini ${ }^{1}$, Nancy Emmanuel ${ }^{2}$, Victor Zibara ${ }^{3}$, Wael D. Terro ${ }^{1}$, Samia Hanna ${ }^{4}$ \\ ${ }^{1}$ Department of Emergency Medicine, Lebanese American University Medical Center, Beirut, Lebanon \\ ${ }^{2}$ Lebanese American University Medical Center, Beirut, Lebanon \\ ${ }^{3}$ Division of Research, Lebanese American University Medical Center, Beirut, Lebanon \\ ${ }^{4}$ Department of Cardiology, Lebanese American University Medical Center, Beirut, Lebanon
}

Corresponding Author: Nancy Emmanuel, Beirut, Lebanon, nancy.emmanuel@lau.edu

Financial support: None

Conflict of Interest: None

Consent: Not applicable

\begin{abstract}
Objective: The purpose of this article is to review the cases of myocarditis in COVID-19 patients and synthesize the current understanding regarding the presentation, diagnosis, and management of myocarditis in the setting of COVID-19 disease.

Background: The novel coronavirus disease has shown serious implications for the cardiovascular system, including acute myocardial injury, arrhythmias, venous thromboembolism, and myocarditis. Several cases of myocarditis in COVID-19 patients have been reported since the disease's emergence at the end of 2019. The diagnostic approach and management have been variable. The purpose of this narrative review is to gather the most reliable published material regarding myocarditis in COVID-19 and present it as an overview to simplify the current understanding we have of this disease.

Methods: We screened PubMed, Scopus, and Embase. We then selected peer-reviewed and pre-print articles published in English that were related to the involvement of the cardiovascular system in COVID19 , with a focus on myocarditis. We included case reports describing myocarditis in COVID-19 patients and summarized their clinical presentation, diagnosis, and management. References of the selected articles were also screened, and some were included when relevant.

Discussion: This article is subdivided into sections that discuss the clinical presentation of COVID-19 myocarditis and move on to various diagnostic approaches and management options. Each subsection presents a brief literature review followed by a summary and interpretation of what was found in the reported cases.
\end{abstract}

Conclusion: After noticing the involvement of the cardiovascular system in COVID-19 patients, specifically through myocarditis, we present this narrative review to provide the medical community with a unified 
article regarding the current understanding of myocarditis in COVID-19 patients. This article further stresses the necessity of establishing proper treatment guidelines for COVID-19 myocarditis.

Keywords: COVID-19, coronavirus, myocarditis, case report, cardiovascular, clinical manifestations, diagnosis, imaging, cardiac magnetic resonance, echocardiography, endomyocardial biopsy, management

\section{Introduction}

A novel severe acute respiratory syndrome coronavirus 2 (SARS-CoV-2) in Wuhan City infected clusters in December 2019 and caused an outbreak of SARS-like respiratory illness worldwide with associated human-to-human transmission [1]. The new coronavirus disease 2019 (COVID-19) outbreak was declared a Public Health Emergency of International Concern by the World Health Organization on January 30, 2020 [2] and upgraded to a pandemic on March 11,2020 [3].

Although COVID-19 mainly manifests with respiratory symptoms, cardiac complications have also been reported in these patients. A study showed that up to $19 \%$ of COVID-19 hospitalized patients demonstrated cardiac injury [4]. The mechanism of cardiac disease is thought to be multifactorial, involving (1) the entry of the SARS-CoV-2 virus into cardiomyocytes, which induces direct cardiotoxicity, and (2) the viral driven inflammatory process with cytokine release, which leads to myocarditis, hypercoagulability, vascular inflammation, and plaque instability [5].

While different cardiac manifestations have been reported in COVID-19, such as ACS, arrhythmias, myocardial injury, and thromboembolism, early studies in China reported that $7-20 \%$ of patients diagnosed with COVID-19 had viral myocarditis [6]. Viral myocarditis caused by the SARS-CoV-2 has also been documented as a cause of dilated cardiomyopathy, albeit in rare case reports $[1,7]$. Although many of these early studies did not include echocardiography or Magnetic Resonance Imaging (MRI) data to assert whether the typical myocarditis features were present in these patients, the number of reports of COVID19 myocarditis published warrants a necessity to review this topic.

\section{Methods}

We screened databases including PubMed, Scopus, and Embase and selected peerreviewed articles published in English that were related to the cardiovascular system's involvement in COVID-19, with a focus on myocarditis. To look for case reports of myocarditis in COVID-19 patients, we performed the search on the PubMed database using the combination of the following keywords: COVID19 , myocarditis, and case report and found 44 results. All the articles found up to July 29, 2020, were screened, and we ended up with 27 case reports describing 29 patients with confirmed COVID-19 who were diagnosed with myocarditis. We summarized their clinical presentations, laboratory findings, diagnostic approach, and treatment, regardless of the country from which these cases were reported. We compared the results to the existing literature regarding myocarditis by screening the databases above using combinations of keywords, including myocarditis, clinical manifestations, diagnosis, imaging, cardiac magnetic resonance, and others. References of the selected articles were screened and included when relevant.

\section{Discussion}

\section{Clinical Presentation}

Patients with acute myocarditis can be asymptomatic and often present with nonspecific symptoms such as chest pain, dyspnea, and palpitations. Those who develop acute heart failure develop dyspnea, fatigue, and exercise intolerance, often with paroxysmal nocturnal dyspnea and orthopnea [1, 8-10]. To note, a viral prodrome with fever, myalgias, and respiratory or gastrointestinal symptoms may be related to myocarditis, though this remains variable [10].

We described patient demographics, including age, sex, ethnicity or nationality, and comorbidities within the supplementary material. As shown in Table 1, we identified the presenting signs and symptoms of the 29 reported cases of COVID-19 myocarditis. We found the clinical presentation to be variable and non-specific. Many patients presented with fever (62.1\%), cough (37.9\%), and dyspnea (51.7\%), which are the typical symptoms in most cases of COVID- 
Table 1: Table showing the presenting signs and symptoms of the 29 reported cases of myocarditis in COVID-19 patients

\begin{tabular}{|c|c|c|c|c|c|c|c|c|}
\hline & \multicolumn{8}{|c|}{ Presenting Signs and Symptoms } \\
\hline & $\begin{array}{l}\text { Chest } \\
\text { pain }\end{array}$ & Dyspnea & Cough & Fatigue & Fever & $\begin{array}{l}\text { Vomiting } \\
\text { Diarrhea }\end{array}$ & Myalgias & Other \\
\hline Sala, Simone et al. [8] & $\checkmark$ & $\checkmark$ & & & & & & \\
\hline Inciardi, Riccardo M et al. [11] & & & $\checkmark$ & $\checkmark$ & $\checkmark$ & & & \\
\hline Kim, In-Cheol et al. [12] & & $\checkmark$ & $\checkmark$ & & $\checkmark$ & $\checkmark$ & & \\
\hline Warchot, Izabela, et al. [13] & & & & & & & & $\checkmark$ \\
\hline Hu, Hongde et al. [14] & $\checkmark$ & $\checkmark$ & & & & $\checkmark$ & & \\
\hline Paul, Jean-François et al. [15] & $\checkmark$ & & & $\checkmark$ & & & & \\
\hline Doyen, Denis et al. [16] & & $\checkmark$ & $\checkmark$ & $\checkmark$ & & $\checkmark$ & & \\
\hline Zeng, Jia-Hui et al. [17] & $\checkmark$ & $\checkmark$ & $\checkmark$ & & $\checkmark$ & & & \\
\hline Coyle, Justin et al. [18] & & $\checkmark$ & $\checkmark$ & & $\checkmark$ & $\checkmark$ & $\checkmark$ & \\
\hline Cizgici, Ahmet Yasar et al. [19] & $\checkmark$ & $\checkmark$ & & & & & & $\checkmark$ \\
\hline Yuan, Wei-Feng et al. [20] & $\checkmark$ & & & & $\checkmark$ & & $\checkmark$ & \\
\hline Irabien-Ortiz, Angela. [21] & $\checkmark$ & & & & $\checkmark$ & & & \\
\hline Radbel, Jared et al. [22] & & $\checkmark$ & $\checkmark$ & & $\checkmark$ & & & \\
\hline $\begin{array}{l}\text { Beşler, Muhammed Said, and Halil } \\
\text { Arslan [23] }\end{array}$ & $\checkmark$ & & & & $\checkmark$ & & & \\
\hline Luetkens, Julian Alexander et al. [24] & & $\checkmark$ & & $\checkmark$ & & & & \\
\hline Hua, Alina et al. [25] & $\checkmark$ & $\checkmark$ & $\checkmark$ & & $\checkmark$ & & & \\
\hline Rehman, Mahin et al. [26] & $\checkmark$ & & & & & & & \\
\hline Craver, Randall et al. [27] & & & & & & $\checkmark$ & & $\checkmark$ \\
\hline Khalid, Nauman et al. [28] & $\checkmark$ & & & & $\checkmark$ & & $\checkmark$ & \\
\hline \multirow{2}{*}{ Gill, Gauravpal S et al. [29] } & $\checkmark$ & $\checkmark$ & & & & & & \\
\hline & $\checkmark$ & $\checkmark$ & & & $\checkmark$ & & & $\checkmark$ \\
\hline $\begin{array}{l}\text { Khatri, Akshay, and Frances Wallach } \\
\text { [30] }\end{array}$ & & $\checkmark$ & $\checkmark$ & $\checkmark$ & $\checkmark$ & & & $\checkmark$ \\
\hline Oberweis, Marie-Laure et al. [31] & & & $\checkmark$ & $\checkmark$ & $\checkmark$ & & & $\checkmark$ \\
\hline Gnecchi, Massimiliano et al. [32] & $\checkmark$ & & & & $\checkmark$ & & & \\
\hline Pavon, Anna Giulia et al. [33] & $\checkmark$ & $\checkmark$ & & & $\checkmark$ & & & \\
\hline Giacomet, Vania et al. [34] & & & & & $\checkmark$ & $\checkmark$ & & \\
\hline Hussain, Hussain et al. [35] & & $\checkmark$ & $\checkmark$ & $\checkmark$ & $\checkmark$ & & & \\
\hline \multirow{2}{*}{$\begin{array}{l}\text { Caballeros Lam, Meylin et } \\
\text { al. [36] }\end{array}$} & $\checkmark$ & & & & & & & \\
\hline & & & $\checkmark$ & & $\checkmark$ & $\checkmark$ & & $\checkmark$ \\
\hline
\end{tabular}

19. Although none of the articles reported patients presenting with paroxysmal nocturnal dyspnea or orthopnea, dyspnea itself was commonly associated with chest pain, with 8 of 29 cases reporting both symptoms combined $(27.6 \%)$. Both of these are non-specific symptoms of acute myocarditis. Chest pain was reported in $55.2 \%$ of cases independently. Many reported cases additionally had fatigue (24.1\%), gastrointestinal symptoms such as vomiting and/or diarrhea (24.1\%), and myalgias (10.3\%), which are non-specific symptoms of viral infections that may be present in viral myocarditis unrelated to COVID-19 as well as in COVID-19 patients without myocarditis. Other less common symptoms such as headaches, dizziness, weight loss, weakness, and odynophagia were reported, each in 1 of the 29 
patients. These occurred combined with one or more of the previously discussed symptoms. Three patients reported syncope and/or near syncope episodes, which is considered one of the clinical syndromes associated with with acute myocarditis, as will be discussed later in the classification section. Two reported cases were already diagnosed with COVID-19. They were suspected of having developed acute viral myocarditis after identification of electrocardiography (ECG) changes. One patient developed a hemodynamically unstable newonset ventricular tachycardia and another one developing ST-segment elevation on ECG. A number of these patients were considered as fulminant myocarditis (17.2\% of the cases) and developed cardiogenic shock $(13.8 \%$ of the cases).

\section{Pathogenesis}

Myocarditis is an inflammatory cardiomyopathy with several clinical and histological presentations [9]. Acute and chronic myocarditis can involve changes in the number and function of lymphocytes and macrophages as well as antibody-mediated injury [9]. This, in turn, causes a cascade of structural and functional changes in cardiomyocytes and ultimately regional or global contractile impairment, conduction system abnormalities, or chamber stiffening.

\section{Classification}

Classification of myocarditis can be either by etiology, histology, immunohistology, or clinicopathological and clinical criteria [9].

Clinical classification seems to be the most practical as many clinical facilities cannot perform endomyocardial biopsy (EMB). The classification is based on increasing diagnostic certainty and includes three categories as per Table 2 [9].

Looking at this classification, we noticed that out of the 29 patients, only one patient had undergone an endomyocardial biopsy, and 1 underwent autopsy and histopathological evaluation after death. Both of these showed positive histological studies confirming a diagnosis of definite myocarditis. Other cases were reported as myocarditis despite commonly falling under probable acute myocarditis.

\section{Diagnostic Testing}

\section{a) ECG Findings}

Most patients with myocarditis have non-specific changes on ECG, including sinus tachycardia, ST-wave and T-wave abnormalities like STsegment elevation or depression, pathologic $Q$ waves, and occasionally atrioventricular or bundle branch block [9, 10]. A widened QRS and $Q$ waves are associated with poor prognosis in acute myocarditis [9]. Pericarditis often manifests with PR depression and diffuse STsegment elevation [9]. The sensitivity of ECG for myocarditis is low (47\%) [9].

The ECGs of the reported cases of COVID-19 myocarditis showed a variety of changes (Table 3). Of the 29 cases reported, 6 did not include the ECG findings of the patient, and 1 case was reported as having a normal ECG. Several patients showed ST-segment elevation; however, some were diffuse [11, 19, 35] while others were localized to specific leads. Due to the ST-segment elevation in some cases,

Table 2: Classification of Myocarditis

Possible subclinical acute myocarditis

\begin{abstract}
Asymptomatic patient with no other causes of acute cardiac disease and with a recent cause for myocarditis
\end{abstract}

Biomarkers of cardiac injury raised, ECG findings suggestive of cardiac injury, or Abnormal cardiac function in echocardiogram or cardiac MRI

Probable acute myocarditis

An individual with all the criteria for possible subclinical myocarditis but also has one of four clinical syndromes consistent with acute myocarditis:

Acute heart failure, chest pain, presyncope or syncope, or myopericarditis
The patient has positive histological studies regardless of any clinical syndrome 
suspicion of myocardial ischemia was raised, and many patients underwent a conventional coronary angiography or a coronary computed tomography angiography to rule out coronary stenosis. In all cases, there was no coronary narrowing $[14,16,19,33]$ except for one case which had mild luminal irregularities [29]. Other patients' ECGs showed non-specific ischemic changes such as T-wave inversions [11, 26]. Tachyarrhythmias, mainly sinus tachycardia, was

Table 3: ECG findings in the reported cases of myocarditis in COVID-19 patients

\begin{tabular}{|c|c|c|}
\hline & & ECG Findings \\
\hline \multicolumn{2}{|l|}{ Sala, Simone et al. [8] } & $\begin{array}{l}\text { Mild ST-segment elevation in leads } V 1-V 2 \text { and aVR, reciprocal ST } \\
\text { depression in V4-V6, and QTC } 452 \mathrm{~ms} \text { with diffuse } U \text {-waves }\end{array}$ \\
\hline \multicolumn{2}{|l|}{ Inciardi, Riccardo M et al. [11] } & $\begin{array}{l}\text { Low voltage in the limb leads, minimal diffuse ST-segment elevation } \\
\text { (more prominent in the inferior and lateral leads), and an ST-segment } \\
\text { depression with T-wave inversion in lead V1 and aVR }\end{array}$ \\
\hline \multicolumn{2}{|l|}{ Kim, In-Cheol et al. [12] } & $\begin{array}{l}\text { Non-specific intraventricular conduction delay and multiple premature } \\
\text { ventricular complexes }\end{array}$ \\
\hline \multicolumn{2}{|l|}{ Warchot, Izabela, et al. [13] } & Not reported \\
\hline \multicolumn{2}{|l|}{ Hu, Hongde et al. [14] } & ST-segment elevation in leads III, aVF \\
\hline \multicolumn{2}{|l|}{ Paul, Jean-François et al. [15] } & repolarization changes in the precordial ECG leads \\
\hline \multicolumn{2}{|l|}{ Doyen, Denis et al. [16] } & $\begin{array}{l}\text { Left ventricular hypertrophy }(L V H) \text { and diffuse inverted } T \text { waves - a } \\
\text { previous ECG showed inverted } T \text { waves in anterior leads only }\end{array}$ \\
\hline \multicolumn{2}{|l|}{ Zeng, Jia-Hui et al. [17] } & Sinus tachycardia and no ST-segment elevation \\
\hline \multicolumn{2}{|l|}{ Coyle, Justin et al. [18] } & Sinus tachycardia without ST-T wave changes \\
\hline \multicolumn{2}{|l|}{ Cizgici, Ahmet Yasar et al. [19] } & $\begin{array}{l}\text { Atrial fibrillation with } 150 \text { beat/min and concave ST elevation except for } \\
\text { aVR lead }\end{array}$ \\
\hline \multicolumn{2}{|l|}{ Yuan, Wei-Feng et al. [20] } & Ventricular tachycardia \\
\hline \multicolumn{2}{|l|}{ Irabien-Ortiz, Angela. [21] } & $\begin{array}{l}\text { Concave ST-segment elevation and PR-segment depression, as well as } \\
\text { low voltages }\end{array}$ \\
\hline \multicolumn{2}{|l|}{ Radbel, Jared et al. [22] } & ST segment depression in leads V4-V6 on ECG, mild global hypokinesis \\
\hline \multicolumn{2}{|c|}{ Beşler, Muhammed Said, and Halil Arslan [23] } & Not reported \\
\hline \multicolumn{2}{|l|}{ Luetkens, Julian Alexander et al. [24] } & Not reported \\
\hline \multicolumn{2}{|l|}{ Hua, Alina et al. [25] } & Concave ST elevation in infero-lateral leads and sinus tachycardia \\
\hline \multicolumn{2}{|l|}{ Rehman, Mahin et al. [26] } & $\begin{array}{l}1 \text { to } 2 \mathrm{~mm} \text { ST elevations in lead I and aVL, ST depression in aVR, mild J- } \\
\text { point elevation, and T-wave inversion in leads II, III and aVF }\end{array}$ \\
\hline \multicolumn{2}{|l|}{ Craver, Randall et al. [27] } & Not reported \\
\hline \multicolumn{2}{|l|}{ Khalid, Nauman et al. [28] } & $\begin{array}{l}\text { Sinus tachycardia with low-amplitude QRS in the precordial and limb } \\
\text { leads, and poor } R \text {-wave progression in the anterior leads }\end{array}$ \\
\hline \multirow[t]{2}{*}{ Gill, Gauravpal S et al. [29] } & Case 1 & $\begin{array}{l}\text { ST-segment elevations in leads I, II, III and aVF with ST-segment } \\
\text { depressions in leads V1-4 }\end{array}$ \\
\hline & Case 2 & $\begin{array}{l}\text { Significant reduction in voltage and subtle PR-segment depressions in } \\
\text { leads II, III and aVF }\end{array}$ \\
\hline \multicolumn{2}{|c|}{ Khatri, Akshay, and Frances Wallach [30] } & $\begin{array}{l}\text { Sinus tachycardia, ST-elevation in leads II, III, aVF and ST-depression in } \\
\text { I, aVL }\end{array}$ \\
\hline \multicolumn{2}{|l|}{ Oberweis, Marie-Laure et al. [31] } & Discrete ST elevation in V3 consistent with pericarditis \\
\hline \multicolumn{2}{|l|}{ Gnecchi, Massimiliano et al. [32] } & Inferolateral ST-segment elevation \\
\hline \multicolumn{2}{|l|}{ Pavon, Anna Giulia et al. [33] } & Not reported \\
\hline \multicolumn{2}{|l|}{ Giacomet, Vania et al. [34] } & Sinus tachycardia without other clear pathologic alterations \\
\hline \multicolumn{2}{|l|}{ Hussain, Hussain et al. [35] } & Diffuse ST elevation \\
\hline \multirow[t]{2}{*}{ Caballeros Lam, Meylin et al. [36] } & Case 1 & Normal ECG \\
\hline & Case 2 & Not reported \\
\hline
\end{tabular}


noted $[17,18,25,28,30,34]$, as well as ventricular tachycardia and atrial fibrillation [2, 19].

\section{b) Laboratory Blood Tests}

Serum biomarkers are elevated in a minority of patients with acute myocarditis. Troponin I has a high specificity (89\%) but a low sensitivity (34\%) in the diagnosis of myocarditis [10]. Increased troponin I is more common than high levels of creatine kinase myocardial band CKMB [10]. Other serum markers of inflammation that are non-specific, such as C-reactive protein, erythrocyte sedimentation rate, and leucocyte count, can be elevated in patients with suspected myocarditis but these markers are of limited value due to their low specificity [9].

Three of the cases did not report any laboratory blood test results $[20,22,27]$. In the rest of the cases, the most reported laboratory blood tests included different combinations of troponin $\mathrm{T}$, Troponin I, N-terminal pro b-type natriuretic peptide (NT-proBNP), and C-Reactive Protein (CRP), all of which, when done, were consistently elevated. Some cases also reported CK-MB levels as high [11, 14, 23, 30, 35]. One case reported an elevated serum myoglobin level [17]. Serum creatine kinase, also known as creatine phosphokinase, was reported as high in two cases [10, 32]. In addition, inflammatory markers like erythrocyte sedimentation rate (ESR), procalcitonin, lactate, and ferritin were reported as high in some cases, and at times they were reported as unremarkable. D-dimers, when reported were found to be elevated $[13,21,26$, 30, 31, 33, 36]. Interleukin 6 (IL-6) was reported as elevated in two cases [31, 34]. Complete blood count and electrolytes were not consistently reported and were not included in Table 4.

\section{c) Imaging Studies}

\section{Echocardiography}

Acute myocarditis does not have any specific features. The most important role of transthoracic echocardiogram (TTE) on the assessment of acute myocarditis is to rule out primary valvular disease, congenital disease, or pericardial constriction [9]. Hence, imaging is used to rule out other causes of heart failure [10]. Many reported cases of myocarditis in COVID-19 patients had normal findings on echocardiography $[15,26,36]$. One patient had no changes compared to his previous echocardiography results; he was already known to have left ventricular hypertrophy due to his chronic hypertension and there were no findings otherwise [16]. Of the 29 cases summarized in this narrative review, 9 cases did not report echocardiography results or reported not having performed an echocardiography due to COVID19 restrictions [13, 19, 20, 22-24, 27, 29, 36]. These cases will be excluded when calculating percentages and the total number of cases will be considered as 20 .

Any new regional or global wall motion abnormality that is not correlated with a coronary distribution has confirmatory and prognostic value in acute myocarditis [9]. Many cases relied on this finding to confirm the diagnosis of acute myocarditis with $15 \%$ reporting diffuse hypokinesia or dyskinesia $[11,17,18]$, and $10 \%$ reporting regional hypokinesis on echocardiography [32, 34]. In fulminant myocarditis, there is a possibility of wall thickening and increased ventricular sphericity [9]. Such findings were not reported in the selected case reports. Left ventricular dysfunction may be found, and $55 \%$ of cases were reported to have a left systolic dysfunction $[8,11,12,14,17,18,28,30,31,34,35]$. However, the strongest predictor of death or need for cardiac transplantation was a loss of right ventricular function $[9,10]$.

In the 29 cases reported, only 2 were found to have right ventricular dysfunction [29, 30]. Both cases were in cardiogenic shock and on inotropic and vasoactive support. The first case underwent pericardiocentesis yielding around $300 \mathrm{~mL}$ of serous fluid, but with worsening status, she was escalated to veno-arterial extracorporeal membrane oxygenation (VAECMO). She later recovered and was discharged successfully [29]. The second case also had to undergo pericardiocentesis which yielded 600 $\mathrm{mL}$ of serosanguinous fluid.

She was also on vasopressor and inotropic support and cardiothoracic surgeons were consulted to initiate ECMO therapy, however, it was not started due to multi-organ failure, and the patient died on day 4 of hospitalization despite maximal supportive care [30] (Table 5). 
Table 4: Laboratory tests results in the reported cases of myocarditis in COVID-19 patients

\begin{tabular}{|c|c|c|c|c|c|c|c|}
\hline & $\begin{array}{l}\text { HS- } \\
\text { Troponin } \\
\mathbf{T} \\
\end{array}$ & $\begin{array}{l}\text { Troponin } \\
\quad T\end{array}$ & $\begin{array}{c}\text { Troponin } \\
1\end{array}$ & $\begin{array}{c}\text { NT- } \\
\text { proBNP }\end{array}$ & $\begin{array}{l}\text { CK- } \\
\text { MB }\end{array}$ & CRP & Other \\
\hline Sala, Simone et al. [8] & $\uparrow$ & & & $\uparrow$ & & $\uparrow$ & \\
\hline $\begin{array}{l}\text { Inciardi, Riccardo M et } \\
\text { al. [11] }\end{array}$ & $\uparrow$ & & & $\uparrow$ & $\uparrow$ & $\uparrow$ & \\
\hline Kim, In-Cheol et al. [12] & & & $\uparrow$ & $\uparrow$ & & & \\
\hline $\begin{array}{l}\text { Warchot, Izabela, et al. } \\
\text { [13] }\end{array}$ & $\uparrow$ & & & $\uparrow$ & & $\uparrow$ & 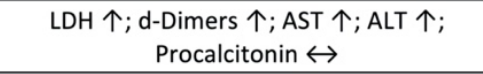 \\
\hline Hu, Hongde et al. [14] & & $\uparrow$ & & $\uparrow$ & $\uparrow$ & & \\
\hline $\begin{array}{l}\text { Paul, Jean-François et } \\
\text { al. [15] }\end{array}$ & & & $\uparrow$ & & & & \\
\hline Doyen, Denis et al. [16] & & & $\uparrow$ & & & & \\
\hline Zeng, Jia-Hui et al. [17] & & & $\uparrow$ & $\uparrow$ & & & Myoglobin $\uparrow$ \\
\hline Coyle, Justin et al. [18] & & & $\uparrow$ & $\uparrow$ & & $\uparrow$ & LDH $\uparrow$ \\
\hline $\begin{array}{l}\text { Cizgici, Ahmet Yasar et } \\
\text { al. [19] }\end{array}$ & & $\uparrow$ & & & & $\uparrow$ & \\
\hline $\begin{array}{l}\text { Irabien-Ortiz, } \\
\text { Angela. [21] }\end{array}$ & & $\uparrow$ & & $\uparrow$ & & $\uparrow$ & D-dimer $\uparrow$ \\
\hline $\begin{array}{l}\text { Beşler, Muhammed } \\
\text { Said, and Halil Arslan } \\
\text { [23] }\end{array}$ & & & $\uparrow$ & $\uparrow$ & $\uparrow$ & $\uparrow$ & \\
\hline $\begin{array}{l}\text { Luetkens, Julian } \\
\text { Alexander et al. [24] }\end{array}$ & $\uparrow$ & & & $\leftrightarrow ; \uparrow$ & & $\uparrow$ & \\
\hline Hua, Alina et al. [25] & & $\uparrow$ & & & & & \\
\hline $\begin{array}{l}\text { Rehman, Mahin et al. } \\
\text { [26] }\end{array}$ & & $\uparrow$ & $\uparrow$ & $\uparrow$ & & $\uparrow$ & 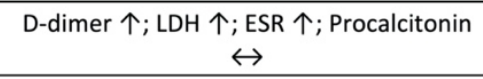 \\
\hline Khalid, & & & $\uparrow$ & & & & High Sensitivity CRP $\uparrow ;$ ESR $\uparrow ; ~ D-d i m e r ~ \uparrow$ \\
\hline $\begin{array}{l}\text { Nauman et } \\
\text { al. [28] }\end{array}$ & & & $\uparrow$ & $\uparrow$ & & & High Sensitivity CRP $\leftrightarrow$; ESR $\leftrightarrow$; Lactate $\uparrow$ \\
\hline
\end{tabular}

\begin{tabular}{|c|c|c|c|c|c|c|c|c|}
\hline \multirow{2}{*}{$\begin{array}{l}\text { Gill, } \\
\text { Gauravpal S } \\
\text { et al. [29] }\end{array}$} & \multicolumn{3}{|l|}{$C 1$} & \multicolumn{4}{|l|}{$\uparrow$} & \multirow{2}{*}{$\begin{array}{l}\text { High Sensitivity CRP } \uparrow ; \text { D-dimer } \uparrow \text {; LDH } \uparrow \text {; } \\
\text { Lactate } \leftrightarrow \\
\text { High Sensitivity CRP } \leftrightarrow \text {; d-dimer } \leftrightarrow \text {; LDH } \\
\leftrightarrow \text {; Lactate } \uparrow\end{array}$} \\
\hline & $C 2$ & & & $\uparrow$ & & & & \\
\hline \multicolumn{2}{|c|}{$\begin{array}{l}\text { Khatri, Akshay, and } \\
\text { Frances Wallach [30] }\end{array}$} & $\uparrow$ & & & & $\uparrow$ & $\uparrow$ & 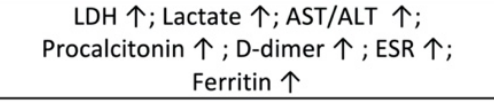 \\
\hline $\begin{array}{l}\text { Oberweis, } \\
\text { Marie-Laure } \\
\text { et al. [31] }\end{array}$ & Peds & $\uparrow$ & & & $\uparrow$ & & $\uparrow$ & D-dimer $\uparrow ; 11-6 \uparrow$ \\
\hline $\begin{array}{l}\text { Gnecchi, } \\
\text { Massimiliano } \\
\text { et al. [32] }\end{array}$ & Peds & & & $\uparrow$ & & & $\uparrow$ & $\mathrm{LDH} \uparrow ; \mathrm{CPK} \uparrow$ \\
\hline \multicolumn{2}{|c|}{$\begin{array}{l}\text { Pavon, Anna Giulia et al. } \\
\text { [33] }\end{array}$} & $\uparrow$ & & & & & & D-dimer $\uparrow$ \\
\hline $\begin{array}{l}\text { Giacomet, } \\
\text { Vania et al. } \\
{[34]}\end{array}$ & Peds & & $\uparrow$ & & $\uparrow$ & & $\leftrightarrow$ & Procalcitonin $\leftrightarrow$; II-6 $\uparrow$ \\
\hline \multicolumn{2}{|c|}{$\begin{array}{l}\text { Hussain, Hussain et } \\
\text { al. [35] }\end{array}$} & & $\uparrow$ & & $\uparrow$ & $\uparrow$ & & \\
\hline \multirow{2}{*}{$\begin{array}{l}\text { Caballeros } \\
\text { Lam, Meylin } \\
\text { et al. [36] }\end{array}$} & $C 1$ & & $\uparrow$ & & & & & \\
\hline & C2/Peds & & $\uparrow$ & & $\uparrow$ & & $\uparrow$ & D-dimer $\uparrow ;$ Ferritin $\uparrow$ \\
\hline
\end{tabular}

Abbreviations: C1: Case 1; C2: Case 2; Peds: Pediatrics Population; ALT: Alanine aminotransferase; AST: Aspartate aminotransferase. $\uparrow$ : Elevated; $\leftrightarrow$ Normal; LDH: Lactate dehydrogenase; CRP: C-reactive protein; ESR: Erythrocyte sedimentation rate; HS-Troponin T: High Sensitivity Troponin T; CK-MB: Creatine kinase-MB; NT-proBNP: N-terminal (NT)-pro hormone BNP 
Table 5: Echocardiographic findings in the reported cases of myocarditis in COVID-19 patients

\begin{tabular}{|c|c|}
\hline & Echocardiography Findings \\
\hline Sala, Simone et al. [8] & $\begin{array}{l}\text { - } \quad \text { Mild left ventricular systolic dysfunction (LVEF 43\%) } \\
\text { - } \quad \text { Inferolateral wall hypokynesis }\end{array}$ \\
\hline $\begin{array}{l}\text { Inciardi, Riccardo } M \text { et } \\
\text { al. [11] }\end{array}$ & $\begin{array}{l}\text { - Normal } \angle V \text { dimensions with increased wall thickness and diffuse echo-bright appearance } \\
\text { of the myocardium. } \\
\text { - } \quad \text { Eiffuse hypokinesis } \\
\text { - } \quad \text { Estimated } \angle V \text { ejection fraction (LVEF) of } 40 \% \text {. } \\
\text { - } \quad \text { Circumferenticular diastolic function mildly impaired with mitral inflow patterns. } \\
\text { - } \quad \text { icardial effusion most notable around the right cardiac chambers }\end{array}$ \\
\hline Kim, In-Cheol et al. [12] & Severe left ventricular (LV) systolic dysfunction \\
\hline Hu, Hongde et al. [14] & $\begin{array}{l}\text { - Enlarged heart and a marked decrease in ventricular systolic function, } L V E F 27 \% \\
\text { - } \quad \text { Trace pericardial effusion }(2 \mathrm{~mm})\end{array}$ \\
\hline $\begin{array}{l}\text { Paul, Jean-François et } \\
\text { al. [15] }\end{array}$ & $\begin{array}{l}\text { - Normal systolic function } \\
\text { - } \quad \text { No pericardial effusion }\end{array}$ \\
\hline Doyen, Denis et al. [16] & $\begin{array}{l}\text { - } \quad \text { Mild } \angle V H \text { (patient known to have } \angle V H \text { attributed to chronic HTN) } \\
\text { - } \quad \angle V E F \text { and wall motion within normal }\end{array}$ \\
\hline Zeng, Jia-Hui et al. [17] & $\begin{array}{ll}\text { - } & \text { Enlarged left ventricle } \\
\text { - } & \text { Diffuse myocardial dyskinesia } \\
\text { - } \quad \text { Low } L \text { VEF (32\%), pulmonary hypertension }(44 \mathrm{mmHg}), \text { normal right cardiac function. } \\
\text { - } \quad \text { No pericardial effusion }\end{array}$ \\
\hline Coyle, Justin et al. [18] & $\begin{array}{l}\text { - } \quad \text { Moderate diffuse hypokinesis (relative apical sparing) } \\
\text { - } \quad \text { NVEF of } 35 \% \text { to } 40 \% \\
\text { - No ventricular dilation or pericardial effusion }\end{array}$ \\
\hline Irabien-Ortiz, Angela. [21] & $\begin{array}{l}\text { - } \quad \text { Moderate concentric hypertrophy } \\
\text { - } \quad \text { Diminished intraventricular volumes with preserved LVEF } \\
\text { - } \quad \text { Moderate pericardial effusion } \\
\text { 2 hours after admission } \\
\text { - Severe biventricular failure and diffuse myocardial edema }\end{array}$ \\
\hline Hua, Alina et al. [25] & $\begin{array}{l}\text { - } \quad \text { Normal left ventricular function } \\
\text { - } \quad \text { Global pericardial effusion with a maximum depth of } 1.1 \mathrm{~cm} \text { and no tamponade }\end{array}$ \\
\hline Rehman, Mahin et al. [26] & $\begin{array}{l}\text { - No wall motion abnormalities } \\
\text { - } \quad \text { Completely normal ejection fraction at } 55 \%-60 \% \\
\text { - No evidence of pericarditis or pericardial effusion. }\end{array}$ \\
\hline Khalid, Nauman et al. [28] & $\begin{array}{l}\text { - } \quad \text { Severe left ventricular systolic dysfunction (EF }=25 \%) \\
\text { - } \quad \text { Large pericardial effusion with signs of pericardial tamponade }\end{array}$ \\
\hline $\begin{array}{l}\text { Gill, Gauravpal S Case } 2 \\
\text { et al. [29] }\end{array}$ & $\begin{array}{l}\text { - } \quad \text { Large pericardial effusion with right ventricular diastolic collapse } \\
\text { - } \quad \text { Severe global biventricular systolic dysfunction with an LVEF of } 20 \% .\end{array}$ \\
\hline $\begin{array}{l}\text { Khatri, Akshay, and Frances } \\
\text { Wallach [30] }\end{array}$ & $\begin{array}{l}\text { - Severe global LV systolic dysfunction, RV enlargement, and RV systolic dysfunction } \\
\text { - Moderate-to-large pericardial effusion anterior to the RV with organizing material } \\
\text { (suggesting an inflammatory process) } \\
\text { Evidence of intermittent RV impaired filling and collapse, suggestive of tamponade } \\
\text { physiology }\end{array}$ \\
\hline $\begin{array}{l}\text { Oberweis, Marie-Laure et } \\
\text { al. [31] }\end{array}$ & $\begin{array}{l}\text { - Normal cardiac anatomy with impaired left ventricular function and trace mitral } \\
\text { insufficiency } \\
\text { - Small pericardial effusion with neither evidence of left ventricular dilatation nor } \\
\text { myocardial hypertrophy or significant pulmonary hypertension }\end{array}$ \\
\hline $\begin{array}{l}\text { Gnecchi, Massimiliano et } \\
\text { al. [32] }\end{array}$ & $\begin{array}{l}\text { - Transthoracic echocardiography showed hypokinesia of the inferior and inferolateral } \\
\text { segments of the } \angle V \\
\text { - } \quad \text { Preserved ejection fraction of } 52 \% \\
\text { - No pericardial effusion }\end{array}$ \\
\hline $\begin{array}{l}\text { Pavon, Anna Giulia et al. } \\
\text { [33] }\end{array}$ & $\begin{array}{l}72 \text { hours after the CMR } \\
\text { - } \quad \text { LVEF at } 47 \% \text {. }\end{array}$ \\
\hline Giacomet, Vania et al. [34] & $\begin{array}{l}\text { - Hypokinesia of the inferior left ventricular wall and the inferior interventricular septum } \\
\text { - } \\
\text { Mild decrease in the } \angle V E F(57-58 \% \text { in parasternal short-axis view, } 52.7 \% \text { in biplane } \\
\text { Simpson's method) } \\
\text { On day 4: } \\
\text { - Ejection fraction recovery with normal left ventricular dimensions } \\
\text { - Persisting mild dyskinesia of the inferior } \angle V \text { wall and the inferior interventricular septum }\end{array}$ \\
\hline Hussain, Hussain et al. [35] & $\begin{array}{l}\text { - Enlarged heart with a marked decrease in ventricular systolic function } \\
\text { - Ejection fraction of } 20 \% \text {. }\end{array}$ \\
\hline $\begin{array}{l}\text { Caballeros Lam, Case } 1 \\
\text { Meylin et al. [36] }\end{array}$ & Normal \\
\hline
\end{tabular}

Abbreviations: LV: Left Ventricular, RV: Right Ventricular, LVH: Left Ventricular Hypertrophy, LVEF: Left Ventricular Ejection Fraction, EF: Ejection Fraction, HTN: hypertension, CMR: Cardiac Magnetic Resonance 
While chest X-Rays performed on COVID 19 patients with myocarditis did not elicit a diagnostic pattern, transthoracic echocardiography revealed a drop in the ejection fraction ranging from mild all the way to severe in patients with no prior history of heart failure. In the cases we reviewed, the lowest ejection fraction reported was $20 \%$ [35].

\section{Cardiac Magnetic Resonance}

Cardiac MRI is being increasingly used as a routine and non-invasive imaging tool for the diagnosis of suspected acute myocarditis and as a means to localize sites for EMB $[9,10]$. In the 29 reported cases of myocarditis in patients diagnosed with COVID-19, 14 did not report or perform a cardiac MRI [14, 17, 19, 21, 22, 25-30, 34, 35].

Among patients with nonischemic dilated cardiomyopathy (DCM) and myocarditis, the correct diagnosis was obtained through cardiac $\mathrm{MRI}$ alone in $80 \%$ of cases [9]. A combination of T2 weighted MRI and post-gadolinium early and late T1 weighted MRI provided the highest sensitivity $(67 \%)$ and specificity $(91 \%)$ for diagnosis [9]. In the reported cases of COVID-19 myocarditis, the combination of increased signal intensity on $\mathrm{T} 2 \mathrm{Wl}$ along with late gadolinium enhancement often confirmed the diagnosis of several cases by fulfilling the Lake Louise criteria $[11,23,24]$. In other cases, the findings on cardiac magnetic resonance did not completely meet the criteria and so the patient was considered to have an atypical myocarditis [20].

The Lake Louise criteria are based on regional or global myocardial signal intensity increase in T2 weighted images, increased global myocardial early gadolinium enhancement ratio between myocardium and skeletal muscle, and late gadolinium enhancement.

\section{d) Histopathology: Endomyocardial Biopsy (EMB)}

The gold standard for the diagnosis of myocarditis is histological or immumohistological evidence of an inflammatory cell infiltrate with or without myocyte damage [9]. Endomyocardial Biopsy (EMB) should be used in a risk vs. benefit approach when there is more prognostic and therapeutic information gained from the biopsy [9]. The American Heart Association/American College of Cardiology/
European Society of Cardiology (AHA/ACC/ESC) joint scientific statement class 1 recommendations include performing $\mathrm{EMB}$ in patients with heart failure with:

"(1) Normal or dilated dimensions of the LV, symptoms for a maximum of 2 weeks duration, and hemodynamic compromise

(2) A dilated ventricle, symptoms lasting from 2 weeks to 3 months, new onset of ventricular arrhythmias, Mobitz type 2 second- or third-degree block, or a failure to respond to care withing 1-2 weeks" [9]

In other clinical scenarios, the use of endomyocardial biopsy remains debatable [10]. However, those with an indication for an EMB should be sent to a medical center with biopsy capability and expertise [10]. To confirm the diagnosis of myocarditis in the reported cases of COVID-19, only one case underwent an endomyocardial biopsy [8]. The medical team refrained from performing a biopsy in the rest of the cases due to several reasons, of which they mentioned: no evidence of heart failure or arrythmias, hemodynamic instability along with significant coagulopathy, rapid and favorable improvement, and establishment of a diagnosis based on the Cardiac Magnetic Resonance (CMR) findings and clinical context. In the case that underwent an EMB, the pathology demonstrated a diffuse infiltrate of $T$ lymphocytes (with a CD3+ $>7 / \mathrm{mm}^{2}$ ) and described a huge area of interstitial edema as well as limited foci of necrosis. There was no replacement fibrosis which suggested the acute nature of the inflammatory process. No SARSCoV-2 genome was detected in the myocardium. No microvascular abnormalities or contraction band necrosis were reported [8].

Another case also had a histopathologic confirmation of the diagnosis, however it was not through an EMB, rather on autopsy, as the patient reported in the case was found pulseless and resuscitation was unsuccessful [27]. Macroscopically, the heart weighed $500 \mathrm{~g}$ (reference for age 262-295 g), was soft, rubbery, mottled, and there were $80 \mathrm{~mL}$ of pericardial fluid. Microscopically, diffuse inflammatory infiltrates were described, with lymphocytes, macrophages, and prominent eosinophils. These were mainly in the interstitium. Multiple foci of myocyte necrosis were found in the RV and LV. There was no evidence of perivascular infiltrates, 
Table 6: CMR findings in the reported cases of myocarditis in COVID-19 patients

\begin{tabular}{|c|c|}
\hline & Cardiac Magnetic Resonance \\
\hline Sala, Simone et al. [8] & $\begin{array}{l}\text { Performed on day } 7 \\
\text { - } \quad \text { Recovery of systolic function (to } 64 \% ; 43 \% \text { on echocardiography) } \\
\text { - } \quad \text { Mild hypokinesia (basal and mid left ventricular segments) } \\
\text { - } \quad \text { Diffuse myocardial edema } \rightarrow \text { wall pseudo-hypertrophy } \\
\text { Absence of detectable myocardial scar/necrotic foci. }\end{array}$ \\
\hline $\begin{array}{l}\text { Inciardi, Riccardo M et } \\
\text { al. [11] }\end{array}$ & $\begin{array}{ll}\text { - } & \text { Increased wall thickness } \\
\text { - } & \text { Diffuse biventricular hypokinesis (especially apical) } \\
\text { - } & \text { Severe LV dysfunction (LVEF of 35\%) } \\
\text { - } \quad \text { Marked biventricular myocardial interstitial edema on T2WI and STIR } \\
\text { - Diffuse late gadolinium enhancement (LGE) extended to the entire biventricular wall. }\end{array}$ \\
\hline Kim, In-Cheol et al. [12] & $\begin{array}{l}\text { - Diffuse high signal intensity (SI) in the LV myocardium } \\
\text { - } \quad \text { Myocardial wall thickening suggesting edema on STIR } \\
\text { Extensive transmural ILGE }\end{array}$ \\
\hline Warchot, Izabela, et al. [13] & $\begin{array}{l}\text { - Left atrial enlargement } \\
\text { - } \quad \text { Global left ventricular hypokinesia with ejection fraction of } 20 \% \\
\text { - } \quad \text { T2WI did not show myocardial edema } \\
\text { intramurally in the basal and mid-cavity segments of the inferior and inferolateral wall and in the apical segments } \\
\text { of the inferior wall }\end{array}$ \\
\hline $\begin{array}{l}\text { Paul, Jean-François et } \\
\text { al. [15] }\end{array}$ & Late subepicardial enhancement predominating in the inferior and lateral walls \\
\hline Doyen, Denis et al. [16] & Subepicardial late gadolinium enhancement of the apex and inferolateral wall). \\
\hline Coyle, Justin et al. [18] & $\begin{array}{ll}- & \text { Recovery of ejection fraction to } 82 \% \\
\text { - } & \text { Diffuse biventricular and bi-atrial edema } \\
\text { - } & \text { Small area of } L G E\end{array}$ \\
\hline Yuan, Wei-Feng et al. [20] & $\begin{array}{l}\text { - High signal intensity on T2WI in the apical region of the left ventricle } \rightarrow \text { possibility of myocardial cell edema } \\
\text { - } \quad \text { the signal of the corresponding segment was normal both in early gadolinium enhancement (EGE) and LGE, } \\
\text { indicating no obvious capillary leakage, myocardial necrosis or interstitial fibrosis. } \\
\text { - Left ventricular systolic function was slightly decreased. }\end{array}$ \\
\hline $\begin{array}{l}\text { Beşler, Muhammed Said, } \\
\text { and Halil Arslan [23] }\end{array}$ & $\begin{array}{l}\text { Performed after one week } \\
\text { - STIR sequence revealed a subepicardial high signal intensity in the mid posterolateral wall of the left ventricle } \\
\text { which suggests myocardial wall edema. } \\
\text { Subepicardial LGE of the posterolateral wall in the mid ventricle-suggestive of myocarditis at } 5 \text { and } 10 \text { min after } \\
\text { contrast administration, respectively }\end{array}$ \\
\hline $\begin{array}{l}\text { Luetkens, Julian Alexander et } \\
\text { al. [24] }\end{array}$ & $\begin{array}{l}\text { Performed day } 10 \text { post-admission } \\
\text { - } \quad \text { Normal left ventricular size } \\
\text { - } \quad \text { Mild systolic dysfunction (LVEF: 49\%) } \\
\text { - } \quad \text { Normal right ventricular volume and function } \\
\text { - } \quad \text { Pericardial effusion mainly around the left ventricular lateral wall } \\
\text { - } \quad \text { Diffuse interstitial myocardial edema onT2WI } \\
\text { - } \quad \text { Presence of diffuse myocardial inflammation was confirmed by T2 mapping } \\
\text { - } \quad \text { GE imaging was negative for focal myocardial lesions, but prolonged T1 relaxation times could be measured }\end{array}$ \\
\hline $\begin{array}{l}\text { Oberweis, Marie-Laure et } \\
\text { al. [31] }\end{array}$ & $\begin{array}{ll}\text { On day 3: } \\
\text { - } & \text { Biventricular systolic dysfunction (LVEF: } 41 \%, \text { RVEF: 46\%) } \\
\text { - } & \text { Small pericardial effusion } \\
\text { - } & \text { Mild subepicardial Gadolinium enhancement of the lateral wall } \\
\text { - } & \text { Signs of diffuse edema }\end{array}$ \\
\hline $\begin{array}{l}\text { Gnecchi, Massimiliano et } \\
\text { al. [32] }\end{array}$ & $\begin{array}{l}\text { - STIR sequences showed changes supporting the diagnosis of acute myocarditis. } \\
\text { - } \\
\text { - T2WI patchy oedema of the lateral wall. } \\
\text { of inferior and inferolateral walls, and patchy oedema pattern involving the whole lateral wall. T2 mapping } \\
\text { sequences confirm the presence of oedema in the same segments. } \\
\text { Late gadolinium sequences reveal high intensity signal indicating necrosis with the same distribution and } \\
\text { localization }\end{array}$ \\
\hline Pavon, Anna Giulia et al. [33] & $\begin{array}{l}\text { - } \quad \text { Reduced left-ventricular (LV) systolic function (LVEF: 42\%) } \\
\text { - } \quad \text { Mild hypokinesia of the lateral wall } \\
\text { - T2-mapping sequences showed myocardial edema } \\
\text { - Subepicardial late gadolinium enhancement (LGE) in the anterior interventricular septum and in the inferior and } \\
\text { inferolateral walls }\end{array}$ \\
\hline \multirow[t]{2}{*}{$\begin{array}{l}\text { Caballeros Lam, Case } 1 \\
\text { Meylin et } \\
\text { al. [36] }\end{array}$} & $\begin{array}{l}\text { - Normal systolic function (LVEF 59\%) } \\
\text { - No regional wall motion abnormalities } \\
\text { High signal intensity on T2 maps and prolonged native } T 1 \text { values in basal and mid-inferoseptal and inferior } \\
\text { myocardial segments } \\
\text { - Late gadolinium enhanced (LGE) images showed mesocardial and subepicardial enhancement of those } \\
\text { segments, representing } 14.2 \% \text { of the total ventricular mass. }\end{array}$ \\
\hline & $\begin{array}{l}\text { - } \quad \text { Normal biventricular function } \\
\text { - } \quad \text { So regional wall motion abnormalities } \\
\text { - } \quad \text { No LGE } \\
\text { - } \quad \text { Small pericardial effusion was noted. }\end{array}$ \\
\hline
\end{tabular}


vascular thrombi, vascular inflammation, or endothelial prominence. No fibrinoid necrosis or granulomatous component was visualized. Only minimal interstitial fibrosis was seen. Although this case was reported as a case of eosinophilic myocarditis in a patient with COVID-19, the authors concluded that this eosinophilic myocarditis is not necessarily specific to the COVID-19 infection, and could instead be idiopathic or resulting from a cardiac decompensation contributed by the SARS-CoV-2.

\section{v. Management}

The management of myocarditis generally depends on the clinical scenario. For possible subclinical acute myocarditis, treatment is not known. If the ventricular function is preserved, patients are reassessed after 1 to 2 weeks for heart failure symptoms or arrhythmias [10]. However, those with an impaired left ventricular ejection fraction (less than 40\%), Angiotensinconverting-enzyme inhibitors (ACEi) or Angiotensin Receptor Blocker (ARB) and possibly a $\beta$ adrenergic blocker is to be given as per the AHA/ACC, Heart Failure Society of America (HFSA), and ESC guidelines for the management of stage $B$ heart failure [10]. In the case of probable acute myocarditis, patients have a good response to standard heart failure treatment as well as avoidance of heavy activity for up to 6 months post infection or until ventricular recovery has been proven [10]. The use of immunosuppressive drugs is not recommended. In addition, there is not enough evidence to recommend use of IV immunoglobulin [10]. In the case of chronic dilated cardiomyopathy, immunosuppression with Azathioprine and prednisone showed improvement in ventricular function and quality of life. The use of antiviral therapy still requires further investigation [10]. As for mechanical circulatory support or extracorporeal membrane oxygenation, these can be used until transplantation or recovery from cardiogenic shock [10]. Survival after transplantation is the same as that of transplantation for other cardiac etiologies [10]. For myopericarditis resembling an acute coronary syndrome, administration of colchicine for around 3 months can help alleviate chest pain related to pericarditis [10]. nonsteroidal anti-inflammatory drug like indomethacin should be kept for patients with normal ventricular function [10]. In the case of syncope from ventricular arrhythmias or heart block, routine management of ventricular arrhythmias due to myocarditis is recommended with hospital admission and ECG monitoring [10]. The use of implantable cardiac defibrillator has the same indications as in non-ischemic DCM but may in some cases be used earlier in giant cell myocarditis [10].

The evidence for the management of myocarditis in COVID-19 is scarce. The mainstay treatment of severe COVID-19 patients with cardiac involvement remains supportive care. General principles in the management include the avoidance of overaggressive hydration, and prevention of hypotension while targeting Mean Arterial Pressure MAP of $60-65 \mathrm{mmHg}$. Dobutamine can be considered in the setting of worsening hypotension with cardiac dysfunction, as well as epinephrine in refractory hypotension [37].

ECMO should be considered for patients with the greatest chance of recovery as well as those with refractory hypoxemia and respiratory acidosis despite advanced ventilation. Patients in cardiogenic shock can benefit from VA ECMO. However, more studies on needed on the topic to better delineate the role of ECMO in COVID19 patients with myocarditis [37].

As for the evidence on anti-inflammatory and anti-viral therapies, a wide range of strategies has been used including but not limited to IVIG, tocilizumab, anakinra, and remdesivir/ritonavir. The data on the effect of the above drugs on cardiac outcome are mainly from case reports and more research is still needed to guide recommendations [37].

Data from our reports showed different management plans for the treated patients. Out of all the reports included in this study, 19 cases reported the management of the patients. Antiviral therapy was initiated in 7 out of 19 cases, with lopinavir/ritonavir use mostly reported. Antibiotics were initiated in 6 cases. IVIG were used in 6 cases. In addition to that, 6 cases reported the use of Hydroxychloroquine, whereas 5 cases out of the 19 reported the use of colchicine. Steroids, mainly Intravenous methylprednisolone, was initiated in 9 cases. Tocilizumab, the drug that blocks the effect of interleukin 6 was administered in 2 cases. 
Table 7: Management of COVID-19 myocarditis patients per case report

\begin{tabular}{|c|c|c|c|c|c|c|c|c|c|}
\hline & Antiviral & HCQ & Steroids & Antibiotic & Vasopressor/Inotrope & IVIG & Colchicine & ECMO & Tocilizumab \\
\hline Sala, Simone et al. [8] & $\mathrm{x}$ & $\mathrm{x}$ & & & & & & & \\
\hline $\begin{array}{l}\text { Inciardi, Riccardo } M \text { et } \\
\text { al. [11] }\end{array}$ & $\mathrm{x}$ & $\mathrm{x}$ & $\mathrm{x}$ & & & & & & \\
\hline Warchot, Izabela, et al. [13] & $x$ & & & $x$ & & & & & \\
\hline Hu, Hongde et al. [14] & & & $x$ & $x$ & $x$ & $x$ & & & \\
\hline Doyen, Denis et al. [16] & & & $x$ & & & & & & \\
\hline Zeng, Jia-Hui et al. [17] & $x$ & & $x$ & $x$ & & $x$ & & $x$ & \\
\hline Coyle, Justin et al. [18] & & $x$ & $x$ & $x$ & $x$ & & $x$ & & $\mathrm{x}$ \\
\hline Irabien-Ortiz, Angela. [21] & $x$ & & $x$ & & & $x$ & & $x$ & \\
\hline $\begin{array}{l}\text { Beşler, Muhammed Said, } \\
\text { and Halil Arslan [23] }\end{array}$ & $\mathrm{x}$ & $\mathrm{x}$ & & $x$ & & & $\mathrm{x}$ & & \\
\hline Hua, Alina et al. [25] & & & & & $\mathrm{x}$ & & & & \\
\hline Khalid, Nauman et al. [28] & & & $\mathrm{x}$ & & $x$ & & $x$ & $x$ & \\
\hline \multirow[t]{2}{*}{ Gill, Gauravpal S et al. [29] } & & & & & & & & $x$ & \\
\hline & & & $x$ & & $\mathrm{x}$ & & $x$ & $\mathrm{x}$ & \\
\hline $\begin{array}{l}\text { Khatri, Akshay, and Frances } \\
\text { Wallach [30] }\end{array}$ & & $x$ & & $\mathrm{x}$ & $x$ & $x$ & & $x$ & \\
\hline $\begin{array}{l}\text { Oberweis, Marie-Laure et } \\
\text { al. [31] }\end{array}$ & & & & & $x$ & $x$ & & & $\mathrm{x}$ \\
\hline $\begin{array}{l}\text { Gnecchi, Massimiliano et } \\
\text { al. [32] }\end{array}$ & $x$ & $x$ & & & & & & & \\
\hline $\begin{array}{l}\text { Pavon, Anna Giulia et al. } \\
\text { [33] }\end{array}$ & & & & & $\mathrm{x}$ & & & & \\
\hline Giacomet, Vania et al. [34] & & & & & & $x$ & & & \\
\hline $\begin{array}{l}\text { Hussain, Hussain et } \\
\text { al. [35] }\end{array}$ & & & $x$ & & $x$ & & $x$ & & \\
\hline
\end{tabular}

Abbreviations: HCQ : Hydroxychloroquine

Vasopressors and inotropes were however used in 9 cases. 6 case reports placed their respective patients on ECMO (Table 7).

\section{Limitations}

This narrative review covers a breadth of literature regarding myocarditis in patients with COVID-19. It is however limited by its methodology as a narrative literature review which entails subjectivity in the way articles are selected and conclusions are drawn. However, within the limitations of the selection criteria and analysis conducted by the authors, we believe it brings valuable knowledge and insight regarding the clinical presentation, diagnosis and management of myocarditis in COVID-19. Further studies and systematic reviews are essential to reach conclusive evidence and establish policies regarding COVID-19 myocarditis.

\section{Conclusions}

After reviewing 29 reported cases of COVID-19 myocarditis we conclude that its clinical presentation is variable with a predominance of fever, cough, dyspnea, and chest pain. Although the clinical classification requires an endomyocardial biopsy to confirm definite myocarditis, only one patient had undergone the histopathological evaluation as part of the diagnostic approach. The rest of the cases mostly relied on the Lake Louise Criteria. Therefore, cardiac magnetic resonance had an important role in the diagnosis of myocarditis. Other diagnostic modalities were also helpful in establishing a diagnosis. Electrocardiography was the most consistently reported modality and commonly showed ST-segment elevation which resulted in a suspicion of myocardial ischemia. Thus, conventional coronary angiography, or a coronary computed tomography angiography were often used to rule out coronary stenosis. On the other hand, serum biomarkers, when reported were found to be elevated, but this may be a bias in reporting. Echocardiography was also helpful, commonly showing wall motion abnormalities. As for the management, it was not consistent. Besides supportive management and the use of COVID-19 targeted antivirals, antibiotics, and anti-inflammatory treatments, several cases reported the use of IVIG and colchicine. This narrative review highlights our current understanding of myocarditis in COVID19 patients and stresses on the necessity of establishing proper treatment guidelines for a better management of COVID-19 myocarditis. 


\section{References}

1. Emmanuel N, Zibara V, Saad JM, et al. COVID-19: What We Know So Far: A Narrative Review. International Journal of Clinical Research. $2020 \quad$ Nov 6;1(1):73-108. https://doi.org/10.38179/ijcr.v1i1.19

2. Harapan H, Itoh N, Yufika A, Winardi W, Keam S, Te H, Megawati D, Hayati Z, Wagner AL, Mudatsir M. Coronavirus disease 2019 (COVID-19): A literature review. J Infect Public Health. 2020 May;13(5):667-673. doi: 10.1016/j.jiph.2020.03.019. Epub 2020 Apr 8. PMID: 32340833; PMCID: $\quad$ PMC7142680. https://doi.org/10.1016/j.jiph.2020.03.019

3. Cucinotta D, Vanelli M. WHO Declares COVID-19 a Pandemic. Acta Biomed. 2020 Mar 19;91(1):157-160. doi: 10.23750/abm.v91i1.9397. PMID: 32191675; PMCID: PMC7569573. https://doi.org/10.23750/abm.v91i1.9397

4. Kochi AN, Tagliari AP, Forleo GB, et al. Cardiac and arrhythmic complications in patients with COVID-19. J Cardiovasc Electrophysiol. 2020 May;31(5):1003-1008. doi: 10.1111/jce.14479. Epub 2020 Apr 13. PMID: 32270559; PMCID: PMC7262150. https://doi.org/10.1111/jce.14479

5. Kang $Y$, Chen T, Mui D, et al. Cardiovascular manifestations and treatment considerations in COVID-19. Heart. 2020 Aug;106(15):1132-1141. doi: 10.1136/heartjnl2020-317056. Epub 2020 Apr 30. PMID: 32354800; PMCID: PMC7211105. https://doi.org/10.1136/heartjnl-2020-317056

6. Nishiga M, Wang DW, Han Y, et al. COVID-19 and cardiovascular disease: from basic mechanisms to clinical perspectives. Nat Rev Cardiol. 2020 Sep;17(9):543-558. doi: 10.1038/s41569-020-0413-9. Epub 2020 Jul 20. PMID: 32690910; PMCID: PMC7370876. https://doi.org/10.1038/s41569-020-0413-9

7. Pollack A, Kontorovich AR, Fuster V, Dec GW. Viral myocarditis--diagnosis, treatment options, and current controversies. Nat Rev Cardiol. 2015 Nov;12(11):670-80. doi: 10.1038/nrcardio.2015.108. Epub 2015 Jul 21. PMID: 26194549. https://doi.org/10.1038/nrcardio.2015.108

8. Sala S, Peretto G, Gramegna M, et al. Acute myocarditis presenting as a reverse Tako-Tsubo syndrome in a patient with SARS-CoV-2 respiratory infection. Eur Heart J. 2020 May 14;41(19):1861-1862. doi: 10.1093/eurheartj/ehaa286. PMID: $\quad 32267502 ; \quad$ PMCID: PMC7184339. https://doi.org/10.1093/eurheartj/ehaa286

9. Sagar S, Liu PP, Cooper LT Jr. Myocarditis. Lancet. 2012 Feb 25;379(9817):738-47. doi: 10.1016/S01406736(11)60648-X. Epub 2011 Dec 18. PMID: 22185868; PMCID: PMC5814111. https://doi.org/10.1016/S01406736(11)60648-X

10. Kapoor JR. Myocarditis. N Engl J Med. 2009 Jul 23;361(4):422-3; author reply 423-4. doi: 10.1056/NEJMc091013. 19625725. https://doi.org/10.1056/NEJMc091013

11. Inciardi RM, Lupi L, Zaccone G, et al. Cardiac Involvement in a Patient With Coronavirus Disease 2019 (COVID-19). JAMA Cardiol. 2020 Jul 1;5(7):819-824. doi: 10.1001/jamacardio.2020.1096. PMID: 32219357; PMCID: PMC7364333.

https://doi.org/10.1001/jamacardio.2020.1096
12. Kim IC, kim JY, kim HA, han S. COVID-19-related myocarditis in a 21-year-old female patient. eur heart J. 2020 may 14;41(19):1859. doi: 10.1093/eurhearti/ehaa288. PMID: 32282027 PMCID:

PMC7184491.

https://doi.org/10.1093/eurheartj/ehaa288

13. Warchoł I, Dębska-Kozłowska A, Karcz-Socha, et al. Terra incognita: clinically suspected myocarditis in a patient with severe acute respiratory syndrome coronavirus 2 infection. Pol Arch Intern Med. 2020 May 29;130(5):446-448. doi: 10.20452/pamw.15309. Epub 2020 Apr 24. PMID: 32329981. https://doi.org/10.20452/pamw.15309

14. Hu H, Ma F, Wei X, Fang $Y$. Coronavirus fulminant myocarditis treated with glucocorticoid and human immunoglobulin. Eur Heart J. 2021 Jan 7;42(2):206. doi: 10.1093/eurheartj/ehaa190. Erratum in: Eur Heart J. 2021 Jan 7;42(2):191. PMID: 32176300; PMCID: PMC7184348. https://doi.org/10.1093/eurheartj/ehaa190

15. Paul JF, charles $P$, richaud $C$, et al. myocarditis revealing COVID-19 infection in a young patient. eur heart $\mathrm{J}$ cardiovasc imaging. 2020 jul 1;21(7):776. doi: 10.1093/ehjci/jeaa107. PMID: $\quad 32338706$; $\quad$ PMCID: $\quad$ PMC7197601. https://doi.org/10.1093/ehjci/jeaa107

16. Doyen D, moceri $\mathrm{P}$, ducreux $\mathrm{D}$, dellamonica $\mathrm{J}$. myocarditis in a patient with COVID-19: A cause of raised troponin and ECG changes. lancet. 2020 may 9;395(10235):1516. doi: 10.1016/S0140-6736(20)30912-0. epub 2020 apr 23. PMID: 32334650; PMCID: PMC7180035. https://doi.org/10.1016/S0140-6736(20)30912-0

17. Zeng JH, liu YX, yuan J, et al. first case of COVID-19 complicated with fulminant myocarditis: A case report and insights. infection. 2020 apr 10:1-5. doi: 10.1007/s15010020-01424-5. epub ahead of print. PMID: 32277408; PMCID: PMC7146072. https://doi.org/10.1007/s15010-020-01424-5

18. Coyle J, igbinomwanhia $E$, sanchez-nadales $A$, et al. A recovered case of COVID-19 myocarditis and ARDS treated with corticosteroids, tocilizumab, and experimental AT-001. JACC case rep. 2020 may 3;2(9):1331-6. doi: 10.1016/j.jaccas.2020.04.025. epub ahead of print. PMID: 32368755; $\quad$ PMCID: $\quad$ PMC7196388. https://doi.org/10.1016/j.jaccas.2020.04.025

19. Cizgici AY, zencirkiran agus $H$, yildiz M. COVID-19 myopericarditis: It should be kept in mind in today's conditions. am J emerg med. 2020 jul;38(7):1547.e51547.e6. doi: 10.1016/j.ajem.2020.04.080. epub 2020 apr 28. PMID: 32360119 ; PMCID: PMC7187845. https://doi.org/10.1016/j.ajem.2020.04.080

20. Yuan WF, tang $X$, zhao $X X$. an 'asymptomatic' driver with COVID-19: Atypical suspected myocarditis by SARS-CoV-2. cardiovasc diagn ther. 2020 apr;10(2):242-243. doi: 10.21037/cdt.2020.03.08. PMID: 32420106; PMCID: PMC7225419. https://doi.org/10.21037/cdt.2020.03.08

21. Irabien-ortiz A. miocarditis fulminante por COVID-19 [fulminant myocarditis due to COVID-19]. rev esp cardiol. 2020 apr 10;73(6):503-4. spanish. doi: 10.1016/j.recesp.2020.04.001. epub ahead of print. PMID: 32292228; PMCID: PMC7151531. https://doi.org/10.1016/j.recesp.2020.04.001

22. Radbel J, narayanan N, bhatt PJ. use of tocilizumab for COVID-19-induced cytokine release syndrome: A cautionary case report. chest. 2020 jul;158(1):e15-e19. doi: 
10.1016/j.chest.2020.04.024. epub 2020 apr 25. PMID: 32343968; PMCID: PMC7195070. https://doi.org/10.1016/j.chest.2020.04.024

23. Beşler MS, arslan $\mathrm{H}$. acute myocarditis associated with COVID-19 infection. am J emerg med. 2020 jun 2:S07356757(20)30463-0. doi: 10.1016/j.ajem.2020.05.100. epub ahead of print. PMID: 32507570; PMCID: PMC7265842. https://doi.org/10.1016/j.ajem.2020.05.100

24. Luetkens $\mathrm{JA}$, isaak $A$, zimmer $S$, et al. diffuse myocardial inflammation in COVID-19 associated myocarditis detected by multiparametric cardiac magnetic resonance imaging. circ cardiovasc imaging. 2020 may;13(5):e010897. doi: 10.1161/CIRCIMAGING.120.010897. epub 2020 may 13. PMID:

https://doi.org/10.1161/CIRCIMAGING.120.010897

25. Hua A, O'gallagher $K$, sado $D$, byrne J. life-threatening cardiac tamponade complicating myo-pericarditis in COVID19. eur heart J. 2020 jun $7 ; 41(22): 2130$. doi: 10.1093/eurheartj/ehaa253. PMID: 32227076; PMCID: PMC7184427. https://doi.org/10.1093/eurheartj/ehaa253

26. Rehman M, Gondal A, Rehman NU. Atypical manifestation of COVID-19-induced myocarditis. Cureus. 2020 jun 18;12(6):e8685. doi: 10.7759/cureus.8685. PMID: 32577331; PMCID: PMC7305571. https://doi.org/10.7759/cureus.8685

27. Craver R, Huber S, Sandomirsky M, et al. Fatal eosinophilic myocarditis in a healthy 17 -year-old male with severe acute respiratory syndrome coronavirus 2 (SARSCoV-2c). fetal pediatr pathol. 2020 jun;39(3):263-268. doi: 10.1080/15513815.2020.1761491. epub 2020 may 13. PMID: 32401577 PMCID:

https://doi.org/10.1080/15513815.2020.1761491

28. Khalid N, chen Y, case BC, et al. COVID-19 (SARS-cov2 ) and the heart - an ominous association. cardiovasc revasc med. 2020 may 15:S1553-8389(20)30256-6. doi: 10.1016/j.carrev.2020.05.009. epub ahead of print. PMID: 32423791; PMCID: PMC7227608. https://doi.org/10.1016/j.carrev.2020.05.009

29. Gill GS, Vlacancich R, Mehta N, et al. spectrum of cardiac involvement in COVID-19. cureus. 2020 jun 15;12(6):e8638. doi: 10.7759/cureus.8638. PMID: 32685307; PMCID: PMC7364403. https://doi.org/10.7759/cureus.8638

30. Khatri A, Wallach F. Coronavirus disease 2019 (covid-19) presenting as purulent fulminant myopericarditis and cardiac tamponade: A case report and literature review. Heart Lung. 2020 Jun 9:S0147-9563(20)30251-X. doi: 10.1016/j.hrtIng.2020.06.003. epub ahead of print. PMID: 32693958; PMCID: PMC7280096. https://doi.org/10.1016/j.hrtlng.2020.06.003

31. Oberweis ML, codreanu A, boehm W, et al. pediatric lifethreatening coronavirus disease 2019 with myocarditis. pediatr infect dis J. 2020 jul;39(7):e147-e149. doi: 10.1097/INF.0000000000002744. PMID: 32427645 https://doi.org/10.1097/INF.0000000000002744

32. Gnecchi M, moretti F, bassi EM, et al. myocarditis in a 16year-old boy positive for SARS-CoV-2. lancet. 2020 jun 27;395(10242):e116. doi: 10.1016/S0140-6736(20)31307-6. PMID: $\quad 32593338 ; \quad$ PMCID: PMC7316465. https://doi.org/10.1016/S0140-6736(20)31307-6
33. Pavon $A G$, meier $D$, samim $D$, et al. first documentation of persistent SARS-cov-2 infection presenting with late acute severe myocarditis. can J cardiol. 2020 jun 6:S0828282X(20)30532-8. doi: 10.1016/j.cjca.2020.06.005. epub ahead of print. 32522523. https://doi.org/10.1016/j.cjca.2020.06.005

34. Giacomet V, manfredini VA, meraviglia G, et al. acute inflammation and elevated cardiac markers in a two-monthold infant with severe acute respiratory syndrome coronavirus 2 infection presenting with cardiac symptoms. pediatr infect dis J. 2020 jul;39(7):e149-e151. doi: 10.1097/INF.0000000000002750. PMID: 32433225. https://doi.org/10.1097/INF.0000000000002750

35. Hussain $\mathrm{H}$, fadel $A$, alwaeli $H$, guardiola $V$. coronavirus (COVID-19) fulminant myopericarditis and acute respiratory distress syndrome (ARDS) in a middle-aged male patient. cureus. 2020 jun 24;12(6):e8808. doi: 10.7759/cureus.8808. PMID: $\quad 32607304$; $\quad$ PMCID: PMC7320646. https://doi.org/10.7759/cureus.8808

36. Caballeros lam $M$, de la fuente villena $A$, hernández hernández $A$, et al. cardiac magnetic resonance characterization of COVID-19 myocarditis. rev esp cardiol (engl ed). 2020 jul 4:S1885-5857(20)30287-5. doi: 10.1016/j.rec.2020.06.018. epub ahead of print. PMID: 32694081; PMCID: PMC7334914. https://doi.org/10.1016/j.rec.2020.06.018

37. Schilling JD, Ravichandran AK, Mandras SA. Management of the Hospitalized COVID-19 Patient With Acute Cardiomyopathy or Heart Failure - American College of Cardiology. 2020 Apr 16. https://www.acc.org/latest-incardiology/articles/2020/04/16/14/42/management-of-thehospitalized-covid-19-coronavirus-2019-patient-with-acutecardiomyopathy-or-heart-failure 